OPEN ACCESS

Edited by:

Reina Villareal,

Baylor College of Medicine,

United States

Reviewed by:

Orvalho Augusto,

University of Washington,

United States

Marc Twagirumukiza,

Ghent University, Belgium

*Correspondence:

Antje Hebestreit

hebestr@/eibniz-bips.de

Specialty section:

This article was submitted to

Obesity,

a section of the journal

Frontiers in Public Health

Received: 20 November 2018

Accepted: 29 October 2019

Published: 21 November 2019

Citation:

Brackmann LK, Buck C,

Nyangasa MA, Kelm S, Sheikh M and Hebestreit A (2019) Anthropometric and Biochemical Predictors for Hypertension in a Cross-Sectional

Study in Zanzibar, Tanzania.

Front. Public Health 7:338 doi: 10.3389/fpubh.2019.00338

\section{Anthropometric and Biochemical Predictors for Hypertension in a Cross-Sectional Study in Zanzibar, Tanzania}

\author{
Lara Kim Brackmann ${ }^{1}$, Christoph Buck ${ }^{2}$, Maria Adam Nyangasa ${ }^{1}$, Soerge Kelm ${ }^{3}$, \\ Mohammed Sheikh ${ }^{4}$ and Antje Hebestreit ${ }^{1 *}$
}

${ }^{1}$ Leibniz Institute for Prevention Research and Epidemiology - BIPS, Department of Epidemiological Methods and Etiological Research, Bremen, Germany, ${ }^{2}$ Leibniz Institute for Prevention Research and Epidemiology - BIPS, Department of Biometry and Data Mangement, Bremen, Germany, ${ }^{3}$ Center for Biomolecular Interactions Bremen, Faculty for Biology and Chemistry, University Bremen, Bremen, Germany, ${ }^{4}$ Environmental Analytical Chemistry and Eco-toxicology Lab, State University of Zanzibar, Zanzibar, Tanzania

Background: Aim of this study was to describe the proportion of hypertension among Zanzibari of different age-groups and to detect possible correlates of this non-communicable disease.

Methods: In 2013 a cross-sectional survey was conducted in Unguja Island, Zanzibar. A total of 235 randomly selected households, including 1,229 (2 to 95 years) eligible study participants, were examined. Association between objectively assessed obesity markers, salt intake and hypertension were investigated. Estimates of $24 \mathrm{~h}$ sodium and potassium excretion from a single morning spot urine specimen were calculated and used as surrogate for salt intake. The association between overweight/obesity and hypertension in different age-groups was assessed in multilevel logistic regression models. Further associations between salt intake and hypertension were analyzed.

Results: Measures of systolic and diastolic blood pressure as well as proportion of overweight/obesity and hypertension both increased with age. Overweight and obesity were significantly associated with hypertension in adults. Moreover, thinness seems to be associated with hypertension as well. We observed a significantly reduced chance of hypertension for higher urinary sodium-to-potassium compared to a lower ratio in children.

Conclusion: Overweight/obesity and hypertension were highly prevalent ( $>47 \%$ of adults $>40$ years are overweight or obese and $>69 \%$ are hypertensive in the same age group) in our sample. Weight status was confirmed as a correlate of high blood pressure in our sample from Zanzibar, Tanzania. To early and effectively prevent related severe cardiovascular outcomes, screening strategies but also monitoring strategies are required for this population.

Keywords: blood pressure, body fat, body mass index, hypertension, salt, sub-Sahara Africa, waist circumference 


\section{INTRODUCTION}

Hypertension is one of the leading causes of death worldwide (1, 2). But in contrast to other cardiovascular risk factors, the risk for hypertension is modifiable (3). While prevalence of hypertension in developed countries stabilizes around $35 \%$ or decreases, the prevalence rises in African countries. An increase of $89 \%$ from 2000 to 2025 is expected (4). By 2025 almost 75\% of hypertensive patients will be found in developing countries (5). Today more than one third of the African adult population is hypertensive (2). And with $46 \%$ prevalence of hypertension in adults older than 25 years, Africa has the highest age-standardized hypertension prevalence worldwide (6). Due to few symptoms, hypertension is poorly detected and, even when detected, often untreated and barely controlled (6-8). Although the risk for hypertension increases with age, in sub-Sahara Africa, even young adults suffer from it $(9,10)$. Higher prevalence is found in lower socio-economic groups and follows demographic gradients from rural to urban areas $(2,3,11)$. Overweight and obesity have been found to be modifiable risk factors for hypertension (12). Furthermore, salt intake is known as another important risk factor for development of hypertension. In African countries high concentrations of salt for food preparation and preservation has been established for a long time, due to poor possibilities of refrigeration or availability of gustatory ingredients (2).

Tanzania is one of Africa's low-income countries. Globalization as well as sedentary lifestyle has noticeable effects on health of the Tanzanian population (11). Like other developing countries, underweight and overweight/obesity and related comorbidities are present in the same population. This results in a rapidly increasing number of non-communicable diseases, such as hypertension and respective risk factors (13). Since obesity and salt intake are two reversible causes for high blood pressure $(3,14)$, we aimed to investigate associations between objectively measured anthropometric and biochemical markers such as urinary sodium and potassium excretion from morning spot urine and blood pressure in different age-groups in a study population from Zanzibar, Tanzania.

\section{MATERIALS AND METHODS \\ Study Design and Participants}

Data collection was conducted in a cross-sectional survey in 2013. Study participants were identified in 244 randomly selected households in Zanzibar, Tanzania. Power calculations, recruiting strategies and general measurement methods were described elsewhere (15). Briefly, the survey was carried out in 80 small administrative Wards (Shehias) in Unguja, one of the two main islands of Zanzibar. Survey sample and study sample are described in Figure 1. Overall, 1,541 individuals were contacted and 98 of them refused to participate. Of the 1,443 participants,

\footnotetext{
Abbreviations: ISCED, International Standard Classification of Education; \% BF, proportion of body fat; BMI, Body Mass Index; NIH, National Institutes of Health; WHO, World Health Organization; WC, waist circumference; SUTAS, Sustainable Use of Tropical Aquatic Systems.
}

214 were excluded for this study due to missing information on age, weight, height and blood pressure measurements.

\section{Data Collection}

Socio-demographic information on sex, age, and education level was collected through an interview-based questionnaire, which was completed for all participants above an age of 2 years. Information on young children were reported by their parents. Questionnaires were developed in English, translated into Swahili, and then back-translated to control for translation errors. All forms and questionnaires were administered and well-explained in Swahili by trained fieldworkers. Educational level of study participants was assessed using the International Standard Classification of Education (ISCED) (16). Based on this classification, we distinguished between low education (no or pre-primary education), primary education (primary school) and secondary education (secondary school and above).

Anthropometric measurements and collection of morning spot urine were carried out in fasting status following standardized procedures (17-19).

All anthropometric measurements and collection of biosamples were carried out considering standard operating procedures and study protocols. The measurement of proportion of body fat $(\% \mathrm{BF})$ and body weight was carried out barefoot using an electronic scale (TANITA BC-420 SMA, Germany) to the nearest $0.1 \mathrm{~kg}$. Height of participants was measured to the nearest $0.1 \mathrm{~cm}$ using a stadiometer (Seca 213 stadiometer, UK) or a measuring board (Seca 417 measuring board, UK) for young children $<2$ years.

Body Mass Index (BMI) was calculated by dividing weight in kilograms by height squared in meters $\left(\mathrm{kg} / \mathrm{m}^{2}\right)$. For adults, overweight was defined as BMI $\geq 25 \mathrm{~kg} / \mathrm{m}^{2}$; obesity was defined as BMI $\geq 30 \mathrm{~kg} / \mathrm{m}^{2}$ according to the WHO (20). For children and adolescents up to an age of 19, BMI was transformed to age-and sex-specific z-score and percentiles using the WHO SAS macros "Anthro"1 and "AnthroPlus" in SAS 9.3 (SAS Institute Inc., Cary, North Carolina, USA). Categories for overweight (BMI between $>75$ th and $<95$ th percentile) and obesity (BMI $>$ 95th percentile) were assigned according to the WHO centile curves (21). Waist circumference (WC) was measured at the midway point between the lower rib margin and the iliac crest in standing position and while wearing light clothing using an inelastic measuring tape (SECA 201) to the nearest $0.1 \mathrm{~cm}$ (22). $\% \mathrm{BF}$ and $\mathrm{WC}$ were categorized into quartiles.

A digital automatic blood pressure monitor (Omron T3) was used to measure the systolic and diastolic blood pressure according to a standardized procedure (15). According to this, participants were asked to rest for at least $15 \mathrm{~min}$ before measurement. Measurements were taken on the naked right upper arm in sitting position with legs uncrossed. The middle of the blood pressure cuff has to be on heart level. Cuff length was determined according to the arm circumference, which was measured to the nearest $0.1 \mathrm{~cm}$ using an inelastic measuring tape (SECA 201). Two measurements were taken at

\footnotetext{
${ }^{1}$ https://www.who.int/childgrowth/software/en/

${ }^{2}$ https://www.who.int/growthref/tools/en/
} 


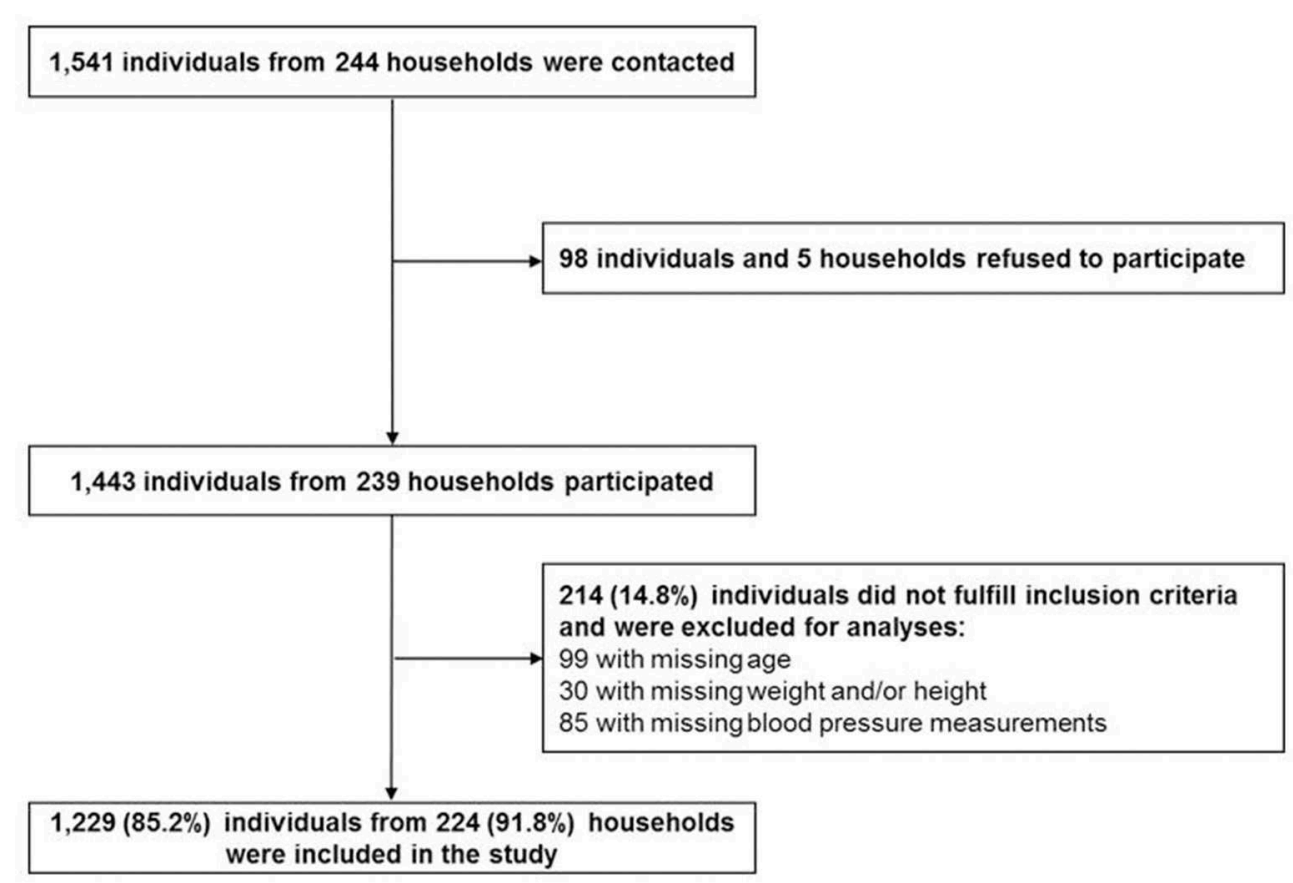

FIGURE 1 | Flow diagram of participants from recruitment to analysis.

an interval of $5 \mathrm{~min}$ plus a third measurement in case of $>5 \%$ difference in blood pressure between the previous two readings. Mean of the two measurements with the smallest difference was taken into analyses. In case of similar differences between the three measurements, mean of all three measurements was taken. Classification was conducted with respect to participants' age. For children, blood pressure between the 90th and 95th percentile were classified as pre-hypertensive. Children with a blood pressure above the 95th percentile were classified as hypertensive (23). Adolescents and adults over 14 years with systolic blood pressure of $\geq 130 \mathrm{mmHg}$ or diastolic blood pressure $\geq 80 \mathrm{mmHg}$ were classified pre-hypertensive. Persons were classified as hypertensive, either if their systolic blood pressure was greater or equal $140 \mathrm{mmHg}$, their diastolic blood pressure reached a value of $\geq 90 \mathrm{mmHg}$ (24) or regular use of anti-hypertensive medication was reported. As prehypertensive native African children have a high risk for developing hypertension in later life (25), pre-hypertensive as well as hypertensive children $(2-\leq 19$ years) were classified as hypertensive for statistical analysis.

Urinary excretion of sodium, potassium and creatinine was measured in a $25 \mathrm{ml}$ fasting status morning spot urine sample by ion-selective electrodes (ErbaLyteCaPlus) or picric acid assay (R\&D creatinine kit). Twenty four hour urinary excretion of sodium and potassium was calculated from this single measurement using the Kawasaki formula (26). For using the Kawasaki formula, $24 \mathrm{~h}$ creatinine excretion was estimated according to another formula by Kawasaki et al. (27) accounting for age, sex, weight and height. Estimated excretion of sodium and potassium was used as surrogates for sodium and potassium intake.

\section{Statistical Analysis}

Descriptive analyses were conducted to calculate sample characteristics regarding systolic and diastolic blood pressure, weight status and urinary excretion of sodium, potassium and creatinine as well as educational level and area of residence stratified by age-groups [young children ( $2-\leq 9$ years), children $(>9-\leq 19$ years), young adults $(>19-\leq 40$ years), adults $(>40$ years)] and sex. Statistics were provided in mean and standard deviation (SD) for continuous variables, and frequency $(\mathrm{N})$ and proportions (\%) for categorical variables.

Multilevel logistic regression was applied to calculate odds ratios (OR) and 95\% confidence intervals (CI) in order to identify associations between anthropometric and biochemical markers with hypertension dichotomized as hypertensive and pre-hypertensive vs. normal blood pressure. Potential clustering within Shehias was considered in terms of a random intercept. With regard to a complete case analysis, item missing in variables included in the study, lead to differing sample size in each regression model. Quartiles of $\% \mathrm{BF}$ and $\mathrm{WC}$ as well as BMI and $24 \mathrm{~h}$ sodium-to-potassium ratio were included as independent variables into each regression model. All models were adjusted for age, sex and area of residence and stratified by age-groups. Since education is highly correlated with age in children, adjustment for educational level for all participants $\leq$ 19 years was done using the highest educational level in their household. For adults, personal information on educational level was used. 
We further adjusted for height in adults $>19$ years and height for age $\mathrm{z}$-scores in children $\leq 19$ years (23). Goodness of fit for all models was determined via the BIC. Statistical analyses were performed using SAS 9.3 (SAS Institute Inc., Cary, North Carolina, USA) and particularly mixed logistic regression models were conducted using the GLIMMIX procedure.

\section{RESULTS}

\section{Study Characteristics}

In this study, a total of 1,229 participants, aged 2-95 years, fulfilled the inclusion criteria. Inclusion of study participants was described in Figure 1. The study sample consisted of 622 children and adolescents aged $2-\leq 19$ years with about $49 \%$ females and 607 adults aged $19+$ years with $60 \%$ females (Table 1).

Mean age for children and adolescents was 11 years and for adults 40 years in both sexes. Proportion of individuals from urban and rural residence was comparable in the sample with an exception in female children $(>9-\leq 19$ years) and male young adults $(>19-\leq 40 \mathrm{y}$.), where about $60 \%$ of participants lived in urban areas.

Concerning participants' weight status, the highest percentage of participants per group changed from severe thinness in young children $(2-\leq 9$ years) over thinness in children and adolescents $(>9-\leq 19$ years) to normal weight or overweight in adults (>19 years). Systolic and diastolic blood pressure (Table 1, Supplementary Table 1) and the prevalence of hypertension and overweight/obesity increased with age (Figure 2, Supplementary Table 1).

\section{Associations Between Anthropometric and Biochemical Markers and Hypertension}

Results of the mixed logistic regression models are shown in Figure 3 and Table 2. Young adults aged $>19-\leq 40$ years, were more likely to be hypertensive or pre-hypertensive if they were overweight $[\mathrm{OR}=3.0$ (95\% CI 1.3, 6.8)], but not obese compared to normal weight participants in the respective age-group. In adults $>40$ years, only obese $[\mathrm{OR}=$ 3.9 (95\% CI 1.3, 11.1)] but not overweight participants were found to be more likely hypertensive compared to normal weight participants.

When comparing the fourth to the first quartile of $\% \mathrm{BF}$, we also observed a significantly higher chance for hypertension in adults $>40$ years $[\mathrm{OR}=3.4(95 \% \mathrm{CI} 1.1,10.8)]$. Furthermore, an increasing chance for hypertension was observed with increasing $\mathrm{BMI}$ as well as with increasing quartiles of $\% \mathrm{BF}$ and $\mathrm{WC}$ in all age-groups, even though not significant.

We further observed a significant association between $24 \mathrm{~h}$ sodium-to-potassium ratio as marker for salt intake and hypertension in children aged $>9-\leq 19$ years $[\mathrm{OR}=0.7(95 \% \mathrm{CI}$ $0.6,0.9)$, for all models (\%BF, WC, BMI)]. Moreover, the direction of association between salt intake and hypertension changes with age. Children with higher salt intake, determined by urinary sodium-to-potassium ratio, were less likely to be hypertensive, whereas higher intake in adults over the age of 40 years was associated with hypertension. In adults, aged 19 to 40 years, salt intake showed no association with hypertension. Variance of random effects in mixed models varied from 0.9 in adults to 1.5 in young children, indicating a considerable amount of unexplained variance on the Shehia level (see Table 2).

\section{DISCUSSION}

This study was part of the SUTAS (Sustainable Use of Tropical Aquatic Systems) survey and was conducted in order to identify anthropometric and biochemical associations with hypertension and pre-hypertension in Unguja Island, Zanzibar, Tanzania. This was the first epidemiological study in Unguja Island, Zanzibar, investigating associations between markers of overweight/obesity and salt intake and hypertension using standardized methods in a randomized sample of members of a household. The most recent surveillance report from the Zanzibar observed systolic and diastolic blood pressure rates and hypertension proportions that were for men and women (age-groups 25-44 years and 45-64 years) lower compared to the respective age-groups of the present study (28). Recently, there have been studies on hypertension in Tanzania $(7,29,30)$, but most of them focus on the adult population of the mainland $(7,30)$. To our knowledge this is the first study providing information on associations between anthropometric and biochemical markers and hypertension not only in adult populations but also for Zanzibari children from an age of 2 years onwards.

In our sample, prevalence of hypertension increased with age, and thus supports the findings of other studies in Tanzania $(7,29)$. Overall, about $16 \%$ of children $(2-\leq 19$ years $)$ in the study population suffered from hypertension. A recent metaanalysis on prevalence of elevated blood pressure in children and adolescents in Africa reported on a prevalence range from 0.2 to $24.8 \%$ (31). Pooling all studies, they found a pooled prevalence of $5.5 \%$ for blood pressure $>95^{\text {th }}$ percentile. However, pooled prevalence in Eastern Africa was found to be higher (9.0\%). In addition, our results are comparable to the reported hypertension prevalence ( $8.4 \%$ up to $24.4 \%$ ) in a South African study investigating children between 5 and 18 years (25). Additionally, $14 \%$ of children ( $2-\leq 19$ years) in our study sample were pre-hypertensive, which corresponds to findings from the respective South African sample and the recent meta-analysis (25, 31 ). In adults (>19 years), prevalence of hypertension was $47 \%$ and considering also the prevalence of pre-hypertension (15\%), the hypertension prevalence in our sample was higher compared to the hypertension prevalence in the whole of Tanzania (39\%), reported by WHO in 2011 (32). However, considering only the age group of adults ( $>40$ years) we found a hypertension prevalence of about $70 \%$, which is similar to the results of a comparable study in adults older than 50 years in South Africa (33).

$\mathrm{BF} \%$ and WC are good indicators for children's weight status (34), but hypertension in children is not only determined by weight but also by height (23). Considering BF\%, WC and BMI as different markers for weight status, logistic regression models including BMI showed the best goodness of fit in young children (2- $\leq 9$ years). This indicates that BMI, including not only weight but also height, seems to be a better predictor for hypertension than other markers of weight status in young children. Participants with higher BMI seemed to be more likely to be hypertensive in all age-groups. A lower BMI was 
TABLE 1 | Characteristics of the study population stratified by age and sex.

\begin{tabular}{|c|c|c|c|c|c|c|c|c|c|c|c|c|c|c|c|c|}
\hline \multirow[b]{3}{*}{ Age [Mean (SD)] } & \multicolumn{4}{|c|}{$\begin{array}{c}\text { Young children }(2-\leq 9 \mathrm{y} .) \\
(N=261 ; 21.2 \%)\end{array}$} & \multicolumn{4}{|c|}{$\begin{array}{l}\text { Children }(>9-\leq 19 \text { y. }) \\
(N=361 ; 29.4 \%)\end{array}$} & \multicolumn{4}{|c|}{$\begin{array}{c}\text { Young adults (>19-40 y.) } \\
(N=327 ; 26.6 \%)\end{array}$} & \multicolumn{4}{|c|}{$\begin{array}{l}\text { Adults (>40 years) } \\
(N=280 ; 22.8 \%)\end{array}$} \\
\hline & \multicolumn{2}{|c|}{$\begin{array}{c}\text { Male } \\
(N=134 ; \\
51.3 \%)\end{array}$} & \multicolumn{2}{|c|}{$\begin{array}{c}\text { Female } \\
(N=127 \\
48.7 \%)\end{array}$} & \multicolumn{2}{|c|}{$\begin{array}{c}\text { Male } \\
(N=186 ; \\
51.5 \%)\end{array}$} & \multicolumn{2}{|c|}{$\begin{array}{c}\text { Female } \\
(N=175 \\
48.5 \%)\end{array}$} & \multicolumn{2}{|c|}{$\begin{array}{c}\text { Male } \\
(N=128 \\
39.1 \%)\end{array}$} & \multicolumn{2}{|c|}{$\begin{array}{c}\text { Female } \\
(N=199 \\
60.9 \%)\end{array}$} & \multicolumn{2}{|c|}{$\begin{array}{c}\text { Male } \\
(N=116 \\
41.4 \%)\end{array}$} & \multicolumn{2}{|c|}{$\begin{array}{c}\text { Female } \\
(N=164 ; \\
58.6 \%)\end{array}$} \\
\hline & 6.1 & $(1.9)$ & 5.8 & $(1.9)$ & 13.9 & $(2.8)$ & 14.0 & $(2.7)$ & 26.3 & (6.3) & 28.8 & (6.6) & 55.7 & (10.1) & 53.3 & $(9.8)$ \\
\hline \multicolumn{17}{|l|}{ Blood pressure [Mean (SD)] } \\
\hline SBP (in mm/Hg) & 103.2 & $(10.9)$ & 103.6 & (12.6) & 116.8 & (13.5) & 116.1 & $(11.8)$ & 128.1 & (13.5) & 125.5 & $(17.0)$ & 155.1 & $(27.2)$ & 153.9 & (32.4) \\
\hline $\mathrm{DBP}$ (in mm/Hg) & 66.6 & $(9.1)$ & 67.6 & $(10.1)$ & 70.5 & $(8.9)$ & 72.9 & $(8.3)$ & 78.1 & $(8.5)$ & 79.5 & (11.2) & 90.8 & (14.0) & 89.6 & $(14.8)$ \\
\hline \multicolumn{17}{|l|}{ Hypertension $[N(\%)]^{\star}$} \\
\hline Yes & 23 & $(17.2)$ & 25 & (19.7) & 20 & (10.8) & 30 & $(17.1)$ & 36 & (28.1) & 52 & (26.1) & 82 & $(70.7)$ & 113 & (68.9) \\
\hline Prehypertension & 21 & $(15.7)$ & 15 & $(11.8)$ & 31 & (16.7) & 20 & $(11.4)$ & 25 & (19.5) & 35 & (17.6) & 16 & $(13.8)$ & 14 & $(8.5)$ \\
\hline \multicolumn{17}{|l|}{ Weight status $^{\dagger}$} \\
\hline Severe thinness & 71 & $(53.0)$ & 52 & $(40.9)$ & 42 & (22.6) & 25 & (14.3) & 7 & (5.5) & 14 & $(7.0)$ & 2 & $(1.7)$ & 5 & (3.0) \\
\hline Thinness & 33 & $(24.6)$ & 48 & $(37.8)$ & 59 & $(31.7)$ & 37 & $(21.1)$ & 14 & $(10.9)$ & 15 & $(7.5)$ & 8 & (6.9) & 9 & $(5.5)$ \\
\hline Normal weight & 30 & $(22.4)$ & 25 & $(19.7)$ & 76 & $(40.9)$ & 89 & $(50.9)$ & 82 & $(64.1)$ & 103 & $(51.8)$ & 51 & $(44.0)$ & 65 & (39.6) \\
\hline Overweight & 0 & $(0.0)$ & 2 & $(1.6)$ & 6 & $(3.2)$ & 16 & $(9.1)$ & 24 & $(18.8)$ & 41 & (20.6) & 40 & $(34.5)$ & 37 & (22.6) \\
\hline Obesity & 0 & $(0.0)$ & 0 & $(0.0)$ & 3 & (1.6) & 8 & (4.6) & 1 & $(0.8)$ & 26 & (13.1) & 15 & (12.9) & 48 & (29.3) \\
\hline \multicolumn{17}{|c|}{ Markers for weight status [Mean (SD)] } \\
\hline BMI (z-score) $)^{\ddagger}$ & -1.6 & $(1.0)$ & -1.4 & $(1.1)$ & -1.1 & $(1.2)$ & -0.5 & $(1.4)$ & & & & & & & & \\
\hline $\mathrm{BMl}$ & & & & & & & & & 22.0 & (3.5) & 23.6 & $(5.0)$ & 24.6 & $(4.5)$ & 26.5 & $(6.9)$ \\
\hline Body fat (in \%) & 14.9 & (3.6) & 14.6 & $(4.8)$ & 10.5 & (5.3) & 20.4 & (7.5) & 15.6 & (8.1) & 27.9 & $(10.5)$ & 21.7 & $(7.4)$ & 34.3 & $(9.7)$ \\
\hline Waist circum-ference (in cm) & 50.4 & $(5.7)$ & 49.5 & $(5.8)$ & 62.7 & (9.8) & 64.9 & $(10.8)$ & 76.4 & (9.0) & 78.7 & (13.5) & 87.1 & (13.9) & 88.6 & (15.4) \\
\hline \multicolumn{17}{|l|}{ Urinary excretion [Mean (SD)] } \\
\hline Sodium (in $\mathrm{mEq} /$ day) $)^{\S}$ & 181.7 & (69.5) & 139.7 & $(51.2)$ & 191.6 & $(71.1)$ & 168.5 & $(58.7)$ & 196.4 & (101.0) & 172.5 & (67.3) & 182.2 & $(70.4)$ & 178.3 & (62.7) \\
\hline Potassium (in $\mathrm{mEq} /$ day) $)^{\S}$ & 36.4 & $(17.8)$ & 27.9 & $(12.9)$ & 40.1 & (21.4) & 33.4 & $(14.0)$ & 38.7 & $(18.6)$ & 36.9 & (22.1) & 38.8 & (20.0) & 36.5 & (15.2) \\
\hline $24 \mathrm{~h}$ sodium- to-potassium ratio & 5.4 & $(1.7)$ & 5.6 & $(2.4)$ & 5.3 & $(1.7)$ & 5.4 & $(1.6)$ & 5.3 & $(1.6)$ & 5.1 & $(1.7)$ & 5.1 & $(1.4)$ & 5.2 & $(1.4)$ \\
\hline Creatinine (in mg/mll) & 1.4 & $(1.0)$ & 1.3 & $(0.9)$ & 1.8 & $(1.3)$ & 1.4 & $(1.0)$ & 2.2 & $(1.3)$ & 1.6 & $(1.1)$ & 2.0 & $(1.2)$ & 1.4 & $(1.1)$ \\
\hline \multicolumn{17}{|l|}{ Education $[N(\%)]^{\mathbb{I I}}$} \\
\hline None or primary & 25 & $(18.7)$ & 29 & $(22.8)$ & 28 & (15.1) & 16 & $(9.1)$ & 22 & (17.3) & 57 & (29.5) & 52 & $(46.4)$ & 92 & (56.8) \\
\hline Secondary or higher & 109 & $(81.3)$ & 98 & $(77.2)$ & 158 & (85.0) & 159 & (90.9) & 105 & (82.7) & 136 & (70.5) & 60 & (53.6) & 70 & (43.2) \\
\hline \multicolumn{17}{|l|}{ Area of residence $[N(\%)]$} \\
\hline Rural & 68 & $(50.8)$ & 58 & $(45.7)$ & 101 & $(54.3)$ & 72 & $(41.1)$ & 49 & $(38.3)$ & 94 & $(47.2)$ & 57 & $(49.1)$ & 83 & $(50.6)$ \\
\hline Urban & 66 & $(49.2)$ & 69 & $(54.3)$ & 85 & $(45.7)$ & 103 & $(58.9)$ & 79 & $(61.7)$ & 105 & (52.8) & 59 & (50.9) & 81 & (49.4) \\
\hline
\end{tabular}

SBP, Systolic blood pressure; DBP, diastolic blood pressure, BMI, body mass index.

"According to NIH (children) (23) and National Heart Foundation (adults) classification (24).

${ }^{\dagger}$ According to WHO classifications (21).

${ }^{\ddagger}$ BMI Z-score was calculated according to WHO (21).

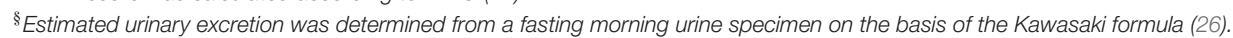

"Measured creatinine from single morning spot specimen.

II According to UNESCO classification of educational levels (16). For children: highest education in household. 


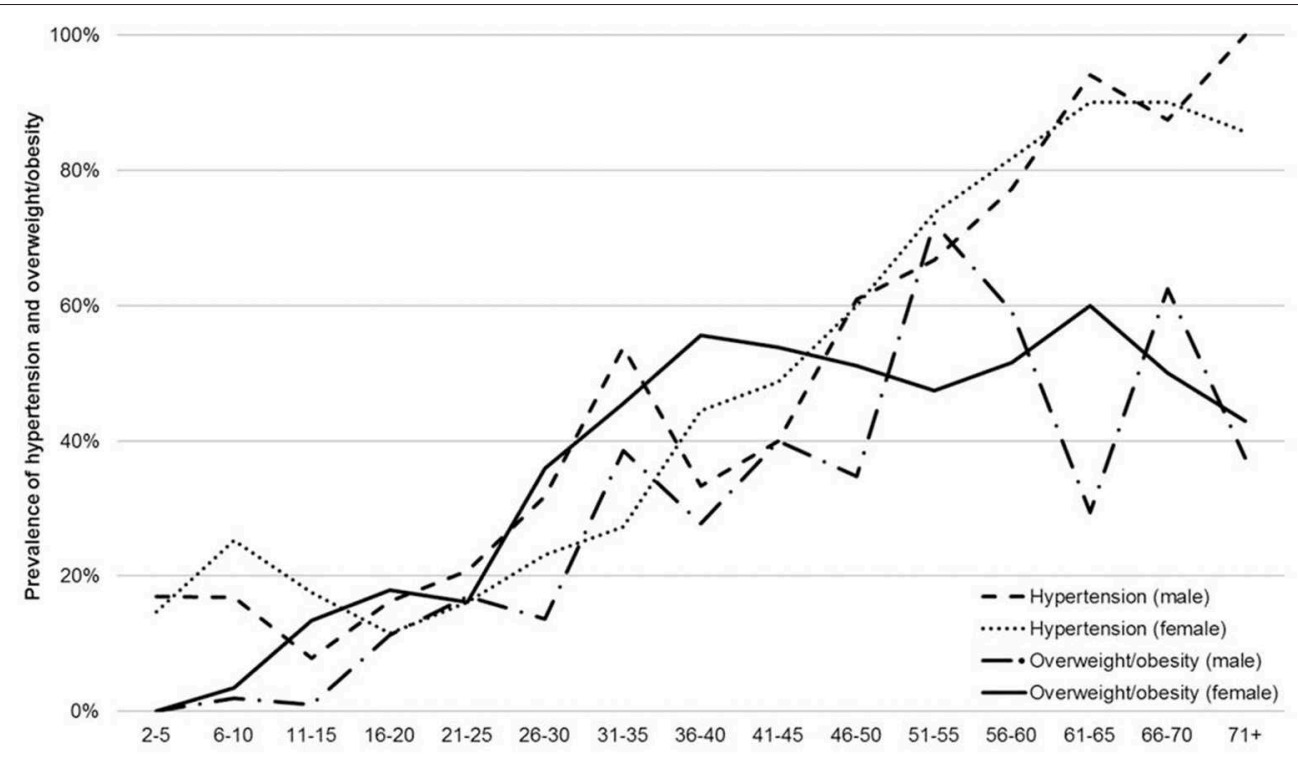

FIGURE 2 | Prevalence of hypertension and of overweight/obesity.

associated with an increased chance for hypertension as well. Only severe thinness in children $<19$ years was found to be preventive regarding high blood pressure. Whereas, models for $\mathrm{WC}$ and $\% \mathrm{BF}$ seems to correlate for the adult population (Figure 3), they were less precise in young $(2-\leq 9$ years) and in older children ( $>9-\leq 19$ years), due to a small number of hypertensive participants and a high prevalence of underweight in these age-groups. Furthermore, $\mathrm{WC}$ and $\% \mathrm{BF}$ as indicator for weight status did not correlate with weight status compared to BMI in our sample: children with (severe) thinness, which were possibly suffering from severe acute malnutrition, such as diseases like Marasmus or Kwashiorkor and might have mislead the classification for markers of weight status due to an altered body composition (35). Additionally, the small sample size may have prevented us from detecting an association between weight status and hypertension in these age-groups.

Since interventions on salt reduction in Sub-Sahara Africa resulted in improved outcome measures of blood pressure and urinary sodium excretion (14), we furthermore expected an association between sodium-to-potassium ratio (as substitute for salt intake) and hypertension in our sample. Previous studies reported that high intake of salt (36-39), especially sodium, was associated with hypertension (40), whereas potassium seemed to act as a preventive factor (41). But contrary to previous findings, we observed a significant decreased hypertension chance associated with a high sodium-to-potassium ratio (higher sodium than potassium excretion) in the age-group $>9-\leq 19$ years. In addition, we observed that a high sodium-to-potassium ratio reduce chance of hypertension $(\mathrm{OR}<1)$ in young children $(2-\leq 9$ years) and children $(>9-\leq 19$ years) as mentioned, but in young adults $(>19-\leq 40$ years) no association was found, while a high sodium-to-potassium ratio was found to be apparent associated $(\mathrm{OR}>1)$ with hypertension in adults $(>40$ years). However, these results should be interpreted carefully. A lower excretion of potassium than sodium in children does not necessarily indicate lower potassium intakes. Potassium is needed especially in somatic growth (42) and can therefore affect the sodium-to-potassium ratio in urine. However, we could not provide a reasonable justification for the observed positive association between lower potassium excretion and a decreased chance of hypertension. Further influencing factors like genetic predispositions $(43-47)$ and early life origins $(48,49)$ should be taken into consideration.

We observed a considerable amount of unexplained variance on the Shehia level, which was more pronounced in children than in adults (see Table 2). Urban and rural areas often differ in topography, distances to daily supplies, access to food and medical services as well as sources of income. Due to the random distribution of Shehias throughout Zanzibar, such area and Shehia level confounders were not measured.

Regarding strengths and limitations, this survey is one of the first ones including an exhaustive study protocol on Zanzibar, Tanzania. It covers anthropometric measurements and biochemical markers of all age-groups in different regions of Unguja Island. Unfortunately, proportion of children $<5$ years of age per household was lower than expected (50) which may have attenuated the effects for the age-group 2 to $\leq$ 9 years (mean age 11 years) due to a smaller sample size. The full sample included individuals from households and Shehias that were both randomly selected. We thus assume that the study sample characterizes the Zanzibari population. Additionally, using the Kawasaki formula we were able to consider creatinine concentration of the urine sample provided, which is a clear strengths of our study. We also investigated a possible non-linear association between the sodium-topotassium ratio and blood pressure in the subsample of salt 

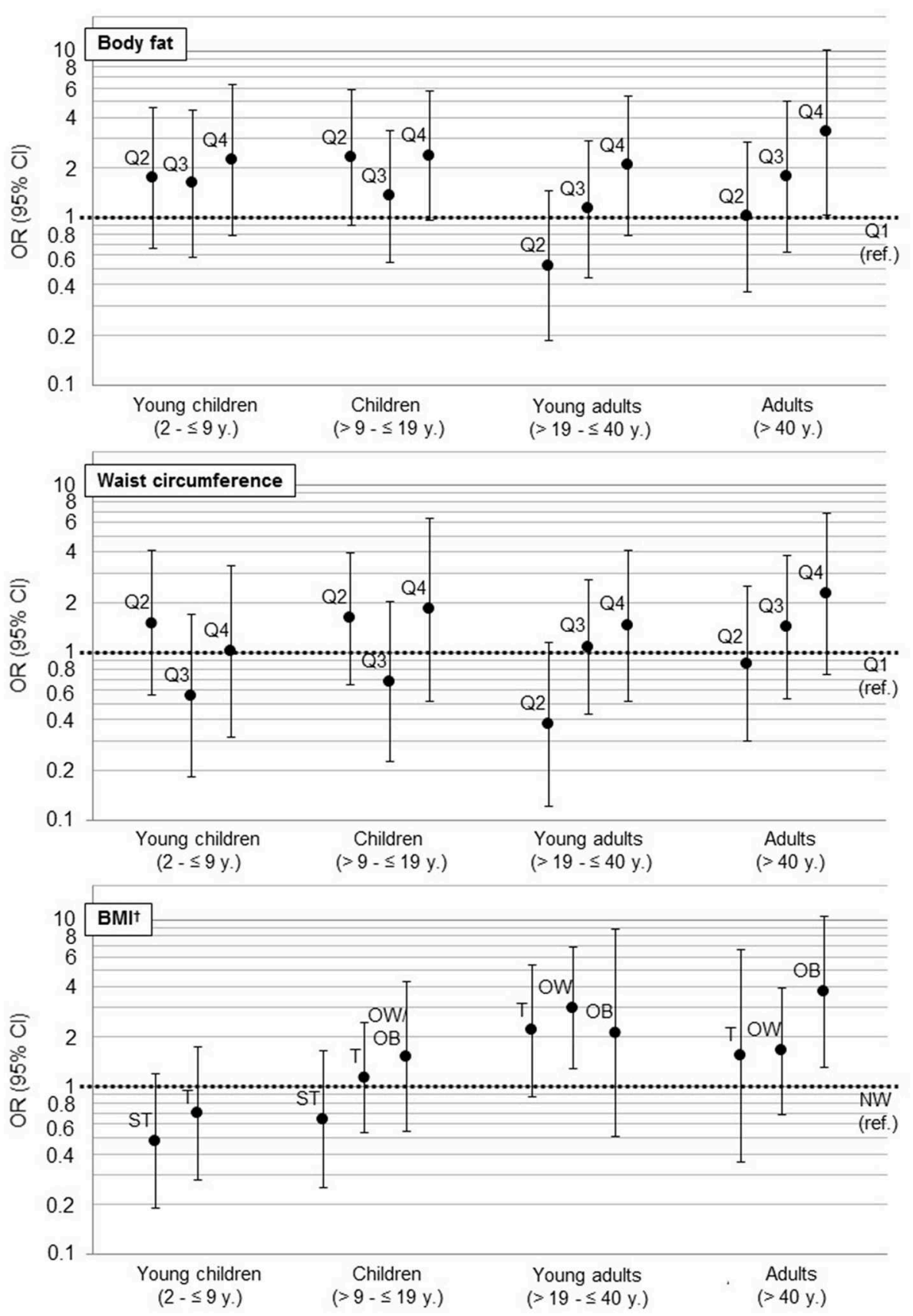

FIGURE 3 | Association of anthropometric markers (WC, BF, BMI, ref: first Quartile) with hypertension as results from multilevel logistic regressions (hypertension: according to NIH (children) (23) and National Heart Foundation (adults) classification (24). For children: hypertension and prehypertension (25)). For a better visual comparison regarding the magnitudes of confidence intervals, we used a log scale. OR, Odds Ratio; Cl, confidence interval; ref., reference; BMI, Body mass index; ST, severe thinness; T, thinness; NW, normal weight; OW, overweight; OB, obesity. ${ }^{\dagger} \mathrm{BMI}$ z-score for children was calculated according to WHO (21).

intake (results not shown). However, in sensitivity analyses cubic regression splines fitted similarly compared to a simple linear univariate regression; thus, we kept the originally conducted linear regression models.

Since the study was performed in a cross-sectional design, it is not possible to attribute the observed significant associations as causal. Therefore, we suggest confirming the reported findings using longitudinal data of a comparable study population. Furthermore, other possible determinants like physical activity could not be taken into account. Although physical activity was measured in this study by uniaxial accelerometer, we did not use the data in our analysis. Data were available only for a 
TABLE 2 | Associated factors with hypertension* detected in multilevel logistic regression models stratified by age.

\begin{tabular}{|c|c|c|c|c|c|c|c|c|}
\hline \multirow{3}{*}{$\begin{array}{l}\text { Model } \\
\text { Young Children (2- } \leq 9 \text { years) }\end{array}$} & \multirow[b]{2}{*}{$N$} & \multicolumn{4}{|c|}{ OR (95\% Cl) } & \multirow[t]{2}{*}{ BIC } & \multicolumn{2}{|c|}{ Between Shehia Variance (SE) } \\
\hline & & \multicolumn{2}{|c|}{ Marker for weight status } & \multicolumn{2}{|c|}{ Sodium-to-potassium ratio } & & & \\
\hline & & & & & & & & \\
\hline Model 1(a): Bodyfat & 170 & & & 1.0 & $(0.9,1.2)$ & 174.1 & 1.5 & $(0.5)$ \\
\hline Q1 & & 1 & (Ref.) & & & & & \\
\hline Q2 & & 1.7 & $(0.7,4.6)$ & & & & & \\
\hline Q3 & & 1.6 & $(0.6,4.4)$ & & & & & \\
\hline Q4 & & 2.2 & $(0.8,6.3)$ & & & & & \\
\hline Model 1(b): Waist circumference & 172 & & & 1.0 & $(0.9,1.2)$ & 170.3 & 1.5 & $(0.5)$ \\
\hline Q1 & & 1 & (Ref.) & & & & & \\
\hline Q2 & & 1.5 & $(0.6,4.1)$ & & & & & \\
\hline Q3 & & 0.6 & $(0.2,1.7)$ & & & & & \\
\hline Q4 & & 1.0 & $(0.3,3.4)$ & & & & & \\
\hline Model 1(c):BMI ${ }^{\dagger}$ & 172 & & & 1.0 & $(0.9,1.2)$ & 161.0 & 1.5 & $(0.4)$ \\
\hline Severe thinness & & 0.5 & $(0.2,1.2)$ & & & & & \\
\hline Thinness & & 0.7 & $(0.3,1.7)$ & & & & & \\
\hline Normal weight & & 1 & (Ref.) & & & & & \\
\hline \multicolumn{9}{|l|}{ Children $(>9-\leq 19$ years) } \\
\hline Model 2(a): Bodyfat & 244 & & & 0.7 & $(0.6,0.9)$ & 311.3 & 1.1 & $(0.4)$ \\
\hline Q1 & & 1 & (Ref.) & & & & & \\
\hline Q2 & & 2.3 & $(0.9,5.9)$ & & & & & \\
\hline Q3 & & 1.3 & $(0.5,3.3)$ & & & & & \\
\hline Q4 & & 2.4 & $(1.0,5.8)$ & & & & & \\
\hline Model 2(b): Waist circumference & 244 & & & 0.7 & $(0.6,0.9)$ & 316.0 & 1.2 & $(0.4)$ \\
\hline Q1 & & 1 & (Ref.) & & & & & \\
\hline Q2 & & 1.6 & $(0.7,4.0)$ & & & & & \\
\hline Q3 & & 0.7 & $(0.2,2.0)$ & & & & & \\
\hline Q4 & & 1.8 & $(0.5,6.4)$ & & & & & \\
\hline Model 2(c): $\mathrm{BMI}^{\dagger}$ & 246 & & & 0.7 & $(0.6,0.9)$ & 320.4 & 1.2 & $(0.4)$ \\
\hline Severe thinness & & 0.6 & $(0.2,1.7)$ & & & & & \\
\hline Thinness & & 1.1 & $(0.5,2.4)$ & & & & & \\
\hline Normal weight & & 1 & (Ref.) & & & & & \\
\hline Overweight/obesity & & 1.5 & $(0.5,4.3)$ & & & & & \\
\hline \multicolumn{9}{|l|}{ Young Adults ( $>19-\leq 40$ years) } \\
\hline Model 3(a): Bodyfat & 198 & & & 1.0 & $(0.8,1.2)$ & 264.6 & 1.0 & $(0.4)$ \\
\hline Q1 & & 1 & (Ref.) & & & & & \\
\hline Q2 & & 0.5 & $(0.2,1.5)$ & & & & & \\
\hline Q3 & & 1.1 & $(0.4,2.9)$ & & & & & \\
\hline Q4 & & 2.0 & $(0.8,5.4)$ & & & & & \\
\hline Model 3(b): Waist circumference & 199 & & & 1.0 & $(0.8,1.2)$ & 266.7 & 1.1 & $(0.4)$ \\
\hline Q1 & & 1 & (Ref.) & & & & & \\
\hline Q2 & & 0.4 & $(0.1,1.2)$ & & & & & \\
\hline Q3 & & 1.1 & $(0.4,2.7)$ & & & & & \\
\hline Q4 & & 1.4 & $(0.5,4.0)$ & & & & & \\
\hline Model 3(c): BMI & 199 & & & 1.0 & $(0.8,1.3)$ & 265.6 & 1.1 & $(0.4)$ \\
\hline Thinness & & 2.2 & $(0.9,5.4)$ & & & & & \\
\hline Normal weight & & 1 & (Ref.) & & & & & \\
\hline Overweight & & 3.0 & $(1.3,6.8)$ & & & & & \\
\hline Obesity & & 2.1 & $(0.5,8.7)$ & & & & & \\
\hline
\end{tabular}


TABLE 2 | Continued

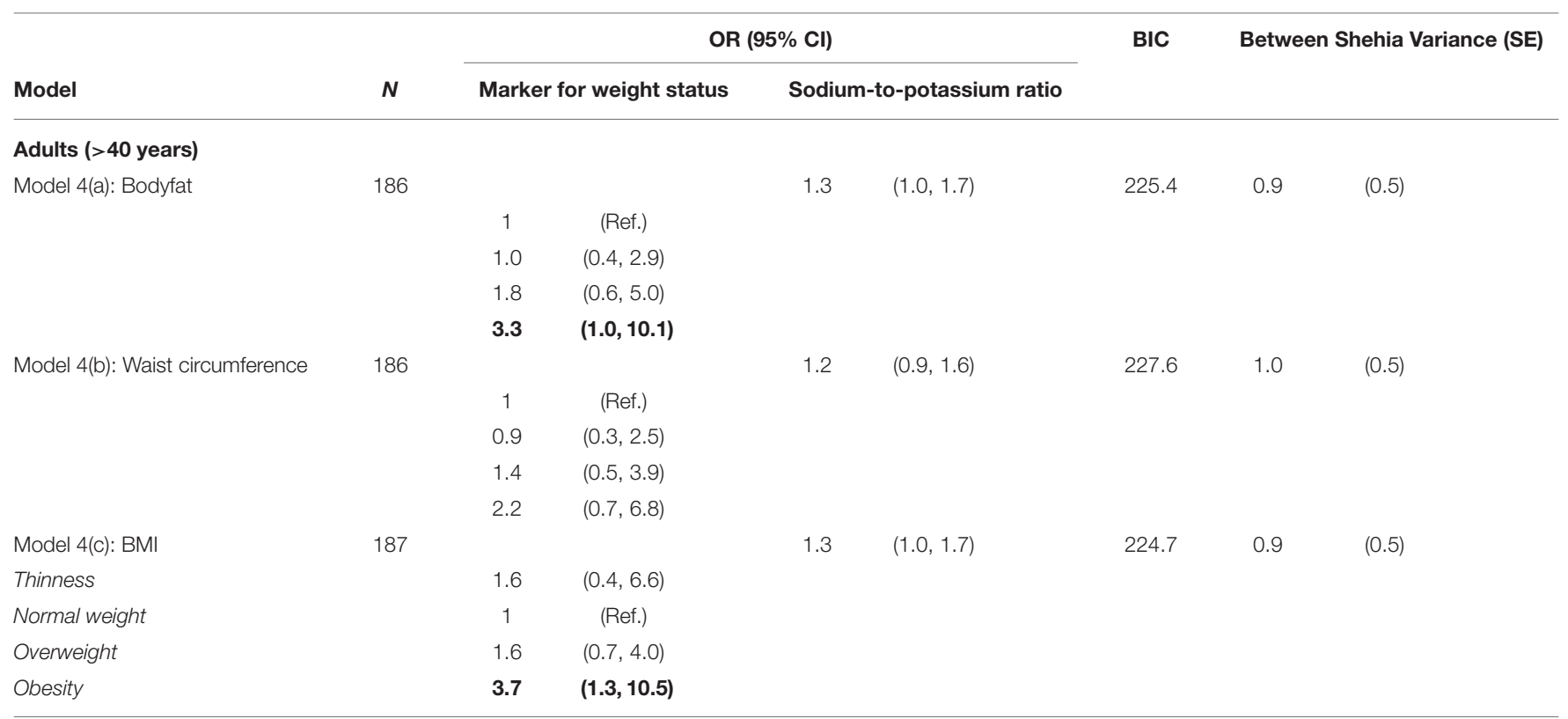

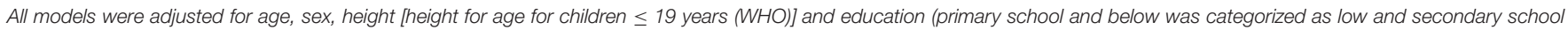
and above as high education (16); for children highest education was used as proxy). Random effects on Shehia level were considered. OR, Odds Ratio; Cl, confidence interval; BIC, Bayesian information criterion; SE, Standard Error, BMI, Body mass index.

${ }^{*}$ According to NIH (children) (23) and National Heart Foundation (adults) classification (24). For children: hypertension and prehypertension (25).

${ }^{\dagger} \mathrm{BMI}$ z-score was calculated according to WHO (21). Bold numbers are statistically significant.

small subsample of children and adolescents, aged between 3 and 16 years, which were randomly selected from 20 Shehias for these measurements. Additionally, there is always a degree of uncertainty with regard to fasting status of participants for at least $12 \mathrm{~h}$ prior to collection of biological samples. However, self-collection of urine potentially affected our data.

Assessing plausible salt intakes is difficult. We therefore decided to use urinary excretion of sodium and potassium as surrogates. Even if previous research indicates that urinary excretion could be used as surrogate for salt intake (51), a difference between intake and excretion cannot be ruled out completely. To our knowledge, there are no existing formulas to calculate $24 \mathrm{~h}$ salt excretions from single morning spot urine that were validated in a sub-Sahara African population for adults as well as for children. We conducted sensitivity analyses using the formulas from Kawasaki et al. (26), from Tanaka et al. (52) and from INTERSALT (53). We did not observe remarkable differences in results when applying different formulas on our study data (data not shown). We decided to use the Kawasaki formula (26), since a consideration of both sodium and potassium is possible using this method.

The interpretation of the association between hypertension and salt excretion from a single measurement had to be considered carefully, since previous studies showed that four to seven urine specimens are needed to estimate sodium-topotassium ratio in hypertensive individuals (54).

\section{CONCLUSION}

Despite the limitations this study to our knowledge is the first to report such associations in a randomly selected population using standardized assessment of anthropometrical and laboratory measurements in Zanzibar.

High blood pressure among Zanzibaris is positively associated with BMI and body composition in >19-95 year olds and is negatively associated with salt intake in $>9-\leq 19$ year olds. Still, there is a tendency that salt intake increases hypertension chance in the age-group 40 years and above. Promotion strategies to reduce hypertension prevalence among Zanzibaris should consider healthy weight maintenance and strategies that facilitate appropriate salt intakes for the population.

For the future, a reduction of the high hypertension prevalence is of high public health interest. There is a need for effective interventions to prevent long-term effects of hypertension and for primary prevention strategies to tackle the rising prevalence using local multidisciplinary approaches considering local lifestyles and eating habits in the local language, Swahili. Continuation of health surveillance initiatives will help to monitor health prevention activities in future. Furthermore, practicing physicians and health professionals should proactively advice and teach patients self-care skills in diet for weight maintenance or weight loss to prevent development of cardiovascular diseases. 


\section{ETHICS STATEMENT}

We certify that all applicable institutional and governmental regulations concerning the ethical use of human volunteers were followed during this research. The study was performed according to the Helsinki Declaration and the study protocol was evaluated and approved by the Ethics Committees of the University of Bremen and of the Zanzibar Ministry of Health and the Zanzibar Medical Research and Ethics Committee. Study participants did not undergo any procedures unless both children and their parents had given consent for examinations, collection of samples, subsequent analysis and storage of personal data and collected samples. Study subjects could consent to single components of the study while abstaining from others. All participants agreed and signed that the data collected during the survey can be stored and used for future analysis.

\section{AUTHOR CONTRIBUTIONS}

$\mathrm{AH}$ was a principal investigator and had the idea of the analysis. LB wrote the paper and had primary responsibility for final content. $\mathrm{CB}$ provided advise for the data analysis. MN involved in the development of the instruments and was responsible for the survey and data management. LB, CB, MN, AH, SK, and MS were responsible for critical revisions and final approval of the manuscript.

\section{REFERENCES}

1. Lim SS, Vos T, Flaxman AD, Danaei G, Shibuya K, Adair-Rohani H, et al. A comparative risk assessment of burden of disease and injury attributable to 67 risk factors and risk factor clusters in 21 regions, 1990-2010: a systematic analysis for the Global Burden of Disease Study 2010. Lancet. (2012) 380:2224-60. doi: 10.1016/S0140-6736(12)61766-8

2. Tibazarwa KB, Damasceno AA. Hypertension in developing countries. Can J Cardiol. (2014) 30:527-33. doi: 10.1016/j.cjca.2014.02.020

3. Mulenga D, Siziya S, Rudatsikira E, Mukonka VM, Babaniyi O, Songolo P, et al. District specific correlates for hypertension in Kaoma and Kasama rural districts of Zambia. Rural Remote Health. (2013) 13:2345. Available online at: https://www.rrh.org.au/journal/article/2345

4. World Health Organization. Global Health Observatory (GHO) Data-Raised Blood Pressure. Geneva: World Health Organization (2012).

5. Kearney PM, Whelton M, Reynolds K, Muntner P, Whelton PK, He J. Global burden of hypertension: analysis of worldwide data. Lancet. (2005) 365:217-23. doi: 10.1016/S0140-6736(05)17741-1

6. Rayner B. Hypertension: detection and management in South Africa. Nephron Clin Pract. (2010) 116:c269-73. doi: 10.1159/000318788

7. Edwards R, Unwin N, Mugusi F, Whiting D, Rashid S, Kissima J, et al. Hypertension prevalence and care in an urban and rural area of Tanzania. $J$ Hypertens. (2000) 18:145-52. doi: 10.1097/00004872-200018020-00003

8. National Institute for Medical Research. Tanzania STEPS Survey Report. London: National Institute for Medical Research (2013).

9. Opie LH, Seedat YK. Hypertension in sub-Saharan African populations. Circulation. (2005) 112:3562-8. doi: 10.1161/CIRCULATIONAHA.105.539569

10. Nyangasa MA, Buck C, Kelm S, Sheikh MA, Brackmann KL, Hebestreit A. Association between cardiometabolic risk factors and body mass index, waist circumferences and body fat in a Zanzibari cross-sectional study. BMJ Open. (2019) 9:e025397. doi: 10.1136/bmjopen-2018025397

\section{FUNDING}

This work was supported by the Leibniz Association and done as part of the Leibniz Graduate School SUTAS (Sustainable Use of Tropical Aquatic Systems) Contract No. SAW-2012-ZMT-4.

\section{ACKNOWLEDGMENTS}

This study would not have been possible without the voluntary collaboration of the Zanzibari families who participated in the extensive examinations. We are grateful for the support from regional and local community leaders and municipalities. The authors gratefully acknowledge the assistance from our fieldworkers Hekima Juma Hamis Sokella, Miza Silima Vuai, Rukia Ali Omar, Nassor Jamal Nassor, Mohamed Mohamed, Kurwa Bakar Mohammed, Ame Khamis Ame and the laboratory technicians Petra Berger and Christina Wege. We furthermore would like to thank Dr. Manuela Siekmeyer from Leipzig University Hospital for helping interpreting the results.

\section{SUPPLEMENTARY MATERIAL}

The Supplementary Material for this article can be found online at: https://www.frontiersin.org/articles/10.3389/fpubh. 2019.00338/full\#supplementary-material

11. Unwin N, Setel P, Rashid S, Mugusi F, Mbanya JC, Kitange H, et al. Noncommunicable diseases in sub-Saharan Africa: where do they feature in the health research agenda? Bull World Health Organ. (2001) 79:947-53. Available online at: https://www.who.int/bulletin/archives/79(10)947.pdf

12. Re RN. Obesity-related hypertension. Ochsner J. (2009) 9:133-6.

13. Maletnlema TN. A Tanzanian perspective on the nutrition transition and its implications for health. Public Health Nutr. (2002) 5:163-8. doi: 10.1079/PHN2001289

14. Muthuri SK, Oti SO, Lilford RJ, Oyebode O. Salt reduction interventions in Sub-Saharan Africa: a systematic review. PLoS ONE. (2016) 11:e0149680. doi: 10.1371/journal.pone.0149680

15. Nyangasa MA, Kelm S, Sheikh MA, Hebestreit A. Design, response rates, and population characteristics of a cross-sectional study in Zanzibar, Tanzania. JMIR Res Protoc. (2016) 5:e235. doi: 10.2196/resprot.6621

16. United Nations Educational Scientific and Cultural Organization (Unesco). International Standard Classification of Education. UNESCO Institute for Statistics (2011).

17. Marfell-Jones M, Olds T, Stewart A, Carter L. International Standards for Anthropometric Assessment. Potchefstroom: International Society for the Advancement of Kinanthropometry (2006).

18. Stomfai S, Ahrens W, Bammann K, Kovacs E, Marild S, Michels N, et al. Intraand inter-observer reliability in anthropometric measurements in children. Int J Obes. (2011) 35(Suppl. 1):S45-51. doi: 10.1038/ijo.2011.34

19. Peplies J, Jimenez-Pavon D, Savva SC, Buck C, Gunther K, Fraterman A, et al. Percentiles of fasting serum insulin, glucose, HbA1c and HOMA-IR in prepubertal normal weight European children from the IDEFICS cohort. Int $J$ Obes. (2014) 38(Suppl. 2):S39-47. doi: 10.1038/ijo.2014.134

20. World Health Organization. Obesity and Overweight Fact Sheet. World Health Organization (2016). Available online at: http://www.who.int/mediacentre/ factsheets/fs311/en/ (accessed August 1, 2017).

21. De Onis M, Garza C, Victora CG. The WHO Multicentre Growth Reference Study: strategy for developing a new international growth reference. Forum Nutr. (2003) 56:238-40. 
22. Marfell-Jones M, Olds T, Stewart A, Carter L. International Standards for Anthropometric Assessment. Potchefstroom: International Society for the Advancement of Kinanthropometry (2006).

23. National Institutes of Health. The fourth report on the diagnosis, evaluation, and treatment of high blood pressure in children and adolescents. Pediatrics. (2005) 114:555-76. doi: 10.1542/peds.114.2.S2.555

24. National Heart Foundation of Australia. Guideline for the Diagnosis and Management of Hypertension in Adults. Melbourne, VIC: National Heart Foundation of Australia (2016).

25. Kagura J, Adair LS, Musa MG, Pettifor JM, Norris SA. Blood pressure tracking in urban black South African children: birth to twenty cohort. BMC Pediatr. (2015) 15:78. doi: 10.1186/s12887-015-0402-z

26. Kawasaki T, Itoh K, Uezono K, Sasaki H. A simple method for estimating $24 \mathrm{~h}$ urinary sodium and potassium excretion from second morning voiding urine specimen in adults. Clin Exp Pharmacol Physiol. (1993) 20:7-14. doi: 10.1111/j.1440-1681.1993.tb01496.x

27. Kawasaki T, Uezono K, Itoh K, Ueno M. [Prediction of 24-hour urinary creatinine excretion from age, body weight and height of an individual and its application]. Nihon Koshu Eisei Zasshi. (1991) 38:567-74.

28. Jorgensen JMA. NCD Survey Report - Main Finings From the National Non-communicable Disease Risk Factor Survey 2011. Zanzibar: Ministry of Health/Danida HSPS IV (2012).

29. Forsyth DM. Hypertension in Tanzania. East Afr Med J. (1969) 46:309-12.

30. Bovet P, Ross AG, Gervasoni JP, Mkamba M, Mtasiwa DM, Lengeler $\mathrm{C}$, et al. Distribution of blood pressure, body mass index and smoking habits in the urban population of Dar es Salaam, Tanzania, and associations with socioeconomic status. Int J Epidemiol. (2002) 31:240-7. doi: 10.1093/ije/31.1.240

31. Noubiap JJ, Essouma M, Bigna JJ, Jingi AM, Aminde LN, Nansseu JR. Prevalence of elevated blood pressure in children and adolescents in Africa: a systematic review and meta-analysis. Lancet Public Health. (2017) 2:e375-86. doi: 10.1016/S2468-2667(17)30123-8

32. World Health Organization. Noncommunicable Diseases Country Profiles 2011. Geneva: World Health Organization (2011).

33. Peltzer K, Phaswana-Mafuya N. Hypertension and associated factors in older adults in South Africa. Cardiovasc J Afr. (2013) 24:67-71. doi: 10.5830/CVJA-2013-002

34. Taylor RW, Jones IE, Williams SM, Goulding A. Evaluation of waist circumference, waist-to-hip ratio, and the conicity index as screening tools for high trunk fat mass, as measured by dual-energy X-ray absorptiometry, in children aged 3-19 y. Am J Clin Nutr. (2000) 72:490-5. doi: 10.1093/ajcn/72.2.490

35. Bender DA. Wellcome classification - a dictionary of food and nutrition (2005).

36. Meneton P, Jeunemaitre X, De Wardener HE, Macgregor GA. Links between dietary salt intake, renal salt handling, blood pressure, and cardiovascular diseases. Physiol Rev. (2005) 85:679-715. doi: 10.1152/physrev.00056.2003

37. He FJ, Macgregor GA. Salt, blood pressure and cardiovascular disease. Curr Opin Cardiol. (2007) 22:298-305. doi: 10.1097/HCO.0b013e32814f1d8c

38. O'donnell MJ, Yusuf S, Mente A, Gao P, Mann JF, Teo K, et al. Urinary sodium and potassium excretion and risk of cardiovascular events. JAMA. (2011) 306:2229-38. doi: 10.1001/jama.2011.1729

39. Mente A, O’donnell MJ, Rangarajan S, Mcqueen MJ, Poirier P, Wielgosz A, et al. Association of urinary sodium and potassium excretion with blood pressure. N Engl J Med. (2014) 371:601-11. doi: 10.1056/NEJMoa1311989

40. Weinberger MH. Sodium, potassium, and blood pressure. Am J Hypertens. (1997) 10:46S-8S. doi: 10.1016/S0895-7061(97)00074-5

41. Aburto NJ, Hanson S, Gutierrez H, Hooper L, Elliott P, Cappuccio FP. Effect of increased potassium intake on cardiovascular risk factors and disease: systematic review and meta-analyses. BMJ. (2013) 346:f1378. doi: 10.1136/bmj.f1378

42. Loh TP, Metz MP. Trends and physiology of common serum biochemistries in children aged 0-18 years. Pathology. (2015) 47:452-61. doi: 10.1097/PAT.0000000000000274

43. Arnett DK, Strogatz DS, Ephross SA, Hames CG, Tyroler HA. Greater incidence of electrocardiographic left ventricular hypertrophy in black men than in white men in Evans County, Georgia. Ethn Dis. (1992) 2:10-7.

44. Sacco RL, Boden-Albala B, Abel G, Lin IF, Elkind M, Hauser WA, et al. Race-ethnic disparities in the impact of stroke risk factors: the northern Manhattan stroke study. Stroke. (2001) 32:1725-31. doi: 10.1161/01.STR.32. 8.1725

45. Mente A, Honey RJ, Mclaughlin JM, Bull SB, Logan AG. High urinary calcium excretion and genetic susceptibility to hypertension and kidney stone disease. J Am Soc Nephrol. (2006) 17:2567-75. doi: 10.1681/ASN.20051 21309

46. Howard G, Lackland DT, Kleindorfer DO, Kissela BM, Moy CS, Judd SE, et al. Racial differences in the impact of elevated systolic blood pressure on stroke risk. JAMA Intern Med. (2013) 173:46-51. doi: 10.1001/2013.jamainternmed.857

47. Pazoki R, Dehghan A, Evangelou E, Warren H, Gao H, Caulfield $\mathrm{M}$, et al. Genetic predisposition to high blood pressure and lifestyle factors: associations with midlife blood pressure levels and cardiovascular events. Circulation. (2018) 137:653-61. doi: 10.1161/CIRCULATIONAHA.117.030898

48. Huxley R, Neil A, Collins R. Unravelling the fetal origins hypothesis: is there really an inverse association between birthweight and subsequent blood pressure? Lancet. (2002) 360:659-65. doi: 10.1016/S0140-6736(02)09834-3

49. Forrester T. Historic and early life origins of hypertension in Africans. J Nutr. (2004) 134:211-6. doi: 10.1093/jn/134.1.211

50. National Bureau of Statistics Tanzania Icf Macro. Tanzania 2010 Demographic and Health Survey, Key Findings. Calverton, MD: NBS and ICF Macro (2011).

51. Food Safety Authority of Ireland. Salt and Health: Review of the Scientific Evidence and Recommendations for Public Policy in Ireland. Dublin: Food Safety Authority of Ireland (2005).

52. Tanaka T, Okamura T, Miura K, Kadowaki T, Ueshima H, Nakagawa H, et al. A simple method to estimate populational 24-h urinary sodium and potassium excretion using a casual urine specimen. J Hum Hypertens. (2002) 16:97-103. doi: $10.1038 /$ sj.jhh.1001307

53. Pfeiffer CM, Hughes JP, Cogswell ME, Burt VL, Lacher DA, Lavoie DJ, et al. Urine sodium excretion increased slightly among U.S. adults between 1988 and 2010. J Nutr. (2014) 144:698-705. doi: 10.3945/jn.113.1 87914

54. Iwahori T, Ueshima H, Torii S, Saito Y, Fujiyoshi A, Ohkubo T, et al. Four to seven random casual urine specimens are sufficient to estimate 24-h urinary sodium/potassium ratio in individuals with high blood pressure. J Hum Hypertens. (2016) 30:328-34. doi: 10.1038/jhh.2015.84

Conflict of Interest: The authors declare that the research was conducted in the absence of any commercial or financial relationships that could be construed as a potential conflict of interest.

Copyright (C) 2019 Brackmann, Buck, Nyangasa, Kelm, Sheikh and Hebestreit. This is an open-access article distributed under the terms of the Creative Commons Attribution License (CC BY). The use, distribution or reproduction in other forums is permitted, provided the original author(s) and the copyright owner(s) are credited and that the original publication in this journal is cited, in accordance with accepted academic practice. No use, distribution or reproduction is permitted which does not comply with these terms. 